\title{
Influence of pressure and silane depletion on microcrystalline silicon material quality and solar cell performance
}

\author{
G. Bugnon, ${ }^{1, a)}$ A. Feltrin, ${ }^{1}$ F. Meillaud, ${ }^{1}$ J. Bailat, ${ }^{2}$ and C. Ballif ${ }^{1}$ \\ ${ }^{1}$ Photovoltaics and Thin Film Electronics Laboratory, Ecole Polytechnique Fédérale de Lausanne (EPFL), \\ Rue A.-L. Breguet 2, CH-2000 Neuchâtel, Switzerland \\ ${ }^{2}$ Oerlikon Solar-Laboratory SA, Rue du Puits-Godet 12a, CH-2000 Neuchâtel, Switzerland
}

(Received 5 December 2008; accepted 5 February 2009; published online 20 March 2009)

\begin{abstract}
Hydrogenated microcrystalline silicon growth by very high frequency plasma-enhanced chemical vapor deposition is investigated in an industrial-type parallel plate R\&D KAI ${ }^{\mathrm{TM}}$ reactor to study the influence of pressure and silane depletion on material quality. Single junction solar cells with intrinsic layers prepared at high pressures and in high silane depletion conditions exhibit remarkable improvements, reaching $8.2 \%$ efficiency. Further analyses show that better cell performances are linked to a significant reduction of the bulk defect density in intrinsic layers. These results can be partly attributed to lower ion bombardment energies due to higher pressures and silane depletion conditions, improving the microcrystalline material quality. Layer amorphization with increasing power density is observed at low pressure and in low silane depletion conditions. A simple model for the average ion energy shows that ion energy estimates are consistent with the amorphization process observed experimentally. Finally, the material quality of a novel regime for high rate deposition is reviewed on the basis of these findings. (C) 2009 American Institute of Physics.
\end{abstract} [DOI: $10.1063 / 1.3095488$ ]

\section{INTRODUCTION}

Thin-film deposition of hydrogenated microcrystalline silicon $(\mu c-\mathrm{Si}: \mathrm{H})$ has attracted a lot of research efforts during these last years. It is of particular interest in the case of photovoltaic applications because of its higher robustness to light-induced degradation, compared to amorphous silicon $(a-\mathrm{Si}: \mathrm{H})$, while providing an enhanced absorption in the near-infrared part of the solar spectrum. ${ }^{1}$ For those reasons, $\mu c-\mathrm{Si}: \mathrm{H}$ has become a material of choice in the development of highly efficient micromorph tandem solar cells when used with an $a-\mathrm{Si}: \mathrm{H}$ top-cell or within triple junction devices. ${ }^{2}$

Despite the strong potential for industrial applications, the deposition conditions by plasma-enhanced chemical vapor deposition (PECVD) favoring device grade $\mu c-\mathrm{Si}: \mathrm{H}$ material quality have yet to be fully understood. In addition, because of its thick active layer requirement (typically, between 1.5 and $2.5 \mu \mathrm{m}$ ), high deposition rates while retaining high material quality are desirable. ${ }^{3-5}$ Presently, these seem to be among the main concerns for lowering industrial manufacturing costs.

A wide range of parameters influences the deposition conditions and hence the material quality of $\mu c-\mathrm{Si}: \mathrm{H}$. First, hardware parameters: electrode geometry, ${ }^{6-8}$ interelectrode distance, ${ }^{9-11}$ and operating frequency. ${ }^{12-14}$ Second, process parameters, easily adjustable for a given reactor: power density, pressure, substrate temperature, and input gas flows. ${ }^{15-19}$ Substrate morphology has been shown to be important as well. $^{20,21}$ Thus, much of the research effort is directed towards the understanding of how these externally adjustable

${ }^{a)}$ Electronic mail: gregory.bugnon@epfl.ch. parameters affect the internal physical plasma characteristics upon which the material quality of $\mu c-\mathrm{Si}: \mathrm{H}$ ultimately depends.

In this study, very high frequency PECVD (VHFPECVD) is used in a R\&D industrial-type $\mathrm{KAI}^{\mathrm{TM}}-\mathrm{S}$ reactor. $\mu c-\mathrm{Si}: \mathrm{H}$ thin films are deposited in different conditions of pressure and silane depletion. It is shown that by increasing the pressure and modifying the hydrogen flow, the microcrystalline material quality can be greatly improved. Structural material characterization of deposited $\mu c-\mathrm{Si}: \mathrm{H}$ layers is presented, and solar cells are prepared to emphasize the impact of the active layer on the solar cell electrical performances. The material quality (i.e., defect density) in different deposition regimes is evaluated by Fourier-transform photocurrent spectroscopy (FTPS). A significant correlation of the intrinsic material quality with the solar cell efficiency is observed, and an interpretation in terms of ion bombardment energy is proposed and supported by a simple model. Based on these findings, the material quality of a novel regime for high rate $\mu c-\mathrm{Si}: \mathrm{H}$ deposition proposed in a recent publication $^{15}$ is reviewed.

\section{EXPERIMENTAL DETAILS}

\section{A. PECVD system}

The $\mathrm{KAI}^{\mathrm{TM}}-\mathrm{S}$ deposition system used for this study was developed by Oerlikon Solar (formerly Unaxis Ltd). This is a smaller version of the large area industrial $\mathrm{KAI}^{\mathrm{TM}}$ systems. ${ }^{22}$ It consists of a closed aluminum plasma reactor (i.e., Plasmabox) contained within a main vacuum chamber. This configuration offers the possibility of a directed pumping from one of the plasma reactor's wall, which allows rapid plasma equilibration time. ${ }^{23}$ Also the differential pumping between the two chambers limits possible cross contaminations from 
the vacuum to the deposition chamber during the process. The lateral dimensions of the Plasmabox are $46 \times 56 \mathrm{~cm}^{2}$ allowing substrate sizes up to $35 \times 45 \mathrm{~cm}^{2}$. A showerhead electrode is suspended at $2.5 \mathrm{~cm}$ from the grounded electrode. VHF power is supplied via a $40.68 \mathrm{MHz}$ generator, feeding the power through an automatic matching-box directly connected to the center of the cathode. The dc self-bias voltage $V_{\mathrm{dc}}$ is measured along with the peak-to-peak voltage $V_{\text {p.p. }}$ with a calibrated high impedance capacitive gauge on the cathode. Isothermal heating is obtained in the deposition chamber and the temperature $T_{s}$ is fixed at $180{ }^{\circ} \mathrm{C}$ for all the depositions in this study.

\section{B. Raman crystallinity measurements}

Micro-Raman spectroscopy was used to measure the crystalline volume fraction $R_{c}$ of the $\mu c-\mathrm{Si}: \mathrm{H}$ layers. ${ }^{24}$ The scattering experiments were performed using the emission line of an $\mathrm{Ar}^{+}$laser at $514 \mathrm{~nm}$ with a Renishaw system 2000. Penetration depth of microcrystalline material at this wavelength is around $150 \mathrm{~nm}$. The evaluation of the crystalline volume fraction was then obtained through the formula

$$
R_{\mathrm{c}}=\frac{I_{510}+I_{520}}{I_{480}+I_{510}+I_{520}},
$$

where $I_{x}$ is the integrated intensity obtained with a Gaussian fit peaked at $x \mathrm{~cm}^{-1}$. Thin films were deposited on Schott AF 45 glass substrates, with a minimum $\mu c-\mathrm{Si}: \mathrm{H}$ layer thickness of $150 \mathrm{~nm}$.

\section{Solar cell preparation and characterization}

Standard $p-i$ - $n$ solar cells were prepared to evaluate the different $\mu c$-Si:H layers. The front contact was a textured zinc oxide $(\mathrm{ZnO})$ thin film, grown on Schott AF 45 glass substrates, obtained through a modified low pressure chemical vapor deposition (LPCVD) process developed at IMT. ${ }^{25}$ Solar cells were deposited in a single chamber process $\mathrm{KAI}^{\mathrm{TM}}{ }_{-} \mathrm{S}$ reactor, with an intrinsic layer of approximately $1.2 \mu \mathrm{m}$. The $i$-layers were grown on top of a thin $\mu c-\mathrm{Si}: \mathrm{H}$ buffer layer above the $p$-layer. The patterned cells were $0.25 \mathrm{~cm}^{2}$ each, and the back contact was obtained through a $\mathrm{ZnO}$ thin film grown using LPCVD as well, covered with a white dielectric reflector. Open circuit voltage $V_{\text {oc }}$ and fill factor (FF) values were derived from current-voltage $(I-V)$ curves, obtained using a Wacom AM1.5 solar simulator, and short-circuit current densities $J_{\text {sc }}$ from external quantum efficiency (EQE) measurements.

\section{Fourier-transform photocurrent spectroscopy}

The material quality of the absorbing $\mu c-\mathrm{Si}: \mathrm{H}$ layer incorporated in each cell was further investigated through FTPS measurements. ${ }^{26}$ The absorption coefficient of lowenergy (sub-band-gap) photons gives important information on the electronic quality of the material: concentration of dangling bonds, i.e., defect density or recombination centers have a significant impact on the absorption value at $0.8 \mathrm{eV}$ and gives an estimation of the midgap defect density. The measurement being very sensitive to the type of $\mathrm{ZnO}$ used (variations of light diffusion and level of doping) a careful attention was given to make sure every cell was prepared using the same type of back and front contacts. Calibration of the absorption curves was performed at $1.35 \mathrm{eV}$ at the corresponding absorption coefficient of crystalline silicon of $235 \mathrm{~cm}^{-1}$.

\section{RESULTS AND DISCUSSION}

\section{A. Study of $\mu c-S i: H$ deposition as a function of pressure}

The first parameter to be studied in the deposition of $\mu c-\mathrm{Si}: \mathrm{H}$ material is the pressure $p$ : Layers are deposited at $1.2,2.5$, and 3.5 mbar. rf input power is kept approximately constant across the three deposition regimes and silane concentration $c$ is below $5 \%$ in the three cases. $c$ is defined here in terms of the input flow rates as $c=\Phi_{\mathrm{SiH}_{4}} /\left(\Phi_{\mathrm{SiH}_{4}}+\Phi_{\mathrm{H}_{2}}\right)$, where $\Phi_{x}$ is the input flow rate of gas $x$ in SCCM (SCCM denotes cubic centimeter per minute at STP). In each deposition regime $c$ is adjusted in order to have a Raman crystallinity fraction $R_{c}$ within the 50\%-60\% range for the intrinsic layer.

In order to clearly separate the effect of pressure and silane depletion, these three deposition regimes were kept in similar depletion conditions. It has been argued that the relevant parameter for the growth of $\mu c-\mathrm{Si}: \mathrm{H}$ is the actual silane concentration in the plasma $c_{p}$ (i.e., the ratio of silicon radicals over hydrogen atoms on the growing film surface) and not only the input silane concentration. ${ }^{15}$ The parameter $c_{p}$ can be estimated with knowledge of the input silane concentration $c$ and silane depletion $D$,

$$
c_{\mathrm{p}}=c(1-D) \text {. }
$$

While $c$ is readily available, silane depletion $D$, which is a function of the plasma dissociation rate and gas residence time, has to be estimated experimentally. As detailed in Ref. 15 , assuming no loss of silicon atoms through polysilane or powder formation and uniform deposition, one can simply evaluate $D$ by comparing the actual deposition rate $R$ to the maximum possible deposition rate $R_{\max }$ (corresponding to $D=1$ ) obtained for a given silane input flow and reactor size through the formula ${ }^{15}$

$$
\frac{R}{R_{\max }}=\frac{D}{1+c(1-D)},
$$

with $R_{\max }$ defined as

$$
R_{\max }=0.0962 \frac{\Phi_{\mathrm{SiH}_{4}}}{A}\left[\AA \mathrm{s}^{-1}\right],
$$

where $A$ is the total deposition area in the PECVD reactor in $\mathrm{m}^{2}$. Inserting the values of the three deposition regimes in the formula above, silane depletion fractions around $45 \pm 10 \%$ are obtained. This is an indication that silane depletion is low and approximately the same in the three $\mu c$-Si:H deposition regimes. We stress that for the three deposition regimes at low silane depletion, the plasma potential measured with the voltage probe is the same within a $10 \%$ error margin. So purely the effect of ion energy reduc- 
TABLE I. Summary of the different $i$-layer deposition conditions presented in this study.

\begin{tabular}{cccccccccc}
\hline \hline $\begin{array}{c}\text { Pressure } \\
(\mathrm{mbar})\end{array}$ & $\begin{array}{c}\Phi_{\mathrm{SiH}_{4}} \\
(\mathrm{SCCM})\end{array}$ & $\begin{array}{c}\Phi_{\mathrm{H}_{2}} \\
(\mathrm{SCCM})\end{array}$ & $\begin{array}{c}c \\
(\%)\end{array}$ & $\begin{array}{c}\text { Power density } \\
\left(\mathrm{W} \mathrm{cm}^{-2}\right)\end{array}$ & $\begin{array}{c}\text { Growth rate } \\
\left(\AA \mathrm{s} \mathrm{s}^{-1}\right)\end{array}$ & $R / R_{\max }$ & $D$ & $\begin{array}{r}V_{\mathrm{rf}} \\
(\mathrm{V})\end{array}$ & $\begin{array}{r}V_{\mathrm{dc}} \\
(\mathrm{V})\end{array}$ \\
\hline 1.2 & 49 & 1250 & 3.8 & 0.13 & 2.9 & 0.34 & 0.35 & 280 & 8 \\
2.5 & 64 & 1140 & 5.3 & 0.15 & 5.2 & 0.50 & 0.51 & 260 & 5 \\
3.5 & 41 & 1566 & 2.6 & 0.17 & 3.2 & 0.47 & 0.47 & 290 & 6 \\
1.2 & 49 & 190 & 20.6 & 0.15 & 6.5 & 0.77 & 0.80 & 225 & 2 \\
2.0 & 75 & 75 & 50.0 & 0.20 & 8.9 & 0.61 & 0.70 & 380 & 5 \\
\hline \hline
\end{tabular}

tion due to pressure increase has been investigated.

This model is valid provided plasma conditions are homogeneous and radical gas phase reactions can be neglected. ${ }^{15}$ We verified in all deposition conditions the spatial homogeneity of the microcrystalline layers in terms of Raman crystalline fraction and growth rates. A homogeneity better than $\pm 10 \%$ was found in all process regimes. The only exception is the high depletion deposition regime at $2.0 \mathrm{mbar}$ (discussed in Sec. III B), where deviations could be observed at the borders of the deposition surface. For this reason high depletion regimes higher than 2.0 mbar were not included in this study. Polysilane and powder formation cannot be ruled out, especially in conditions of highest pressure and silane depletion. However, because of the good spatial homogeneity, they should be limited. In case of important powder formation, these values would represent lower boundaries for silane depletion. In addition, as can be verified by a simple one-dimensional plasma model, ${ }^{27}$ uniform deposition using this gas flow configuration can be achieved provided the pressure drop $\Delta p / p$ across the reactor remains small, which is verified for areas smaller than $0.5 \mathrm{~m}^{2}$, even with pumping done along a single side (the reactor's size used in this study is $0.26 \mathrm{~m}^{2}$ ).

Solar cells were deposited with their intrinsic layer prepared in the three regimes described in the previous paragraph, which are detailed in Table I. The $I-V$ curves from the best cells obtained in those three regimes are shown in Fig. 1. Major improvements are observed for the cells prepared at higher pressure. $V_{\mathrm{oc}}, \mathrm{FF}$, and $J_{\mathrm{sc}}$ are all increased significantly, with pressure ranging from 0.34 to $0.52 \mathrm{~V}, 52 \%$ to $72 \%$, and from 18.8 to $22.2 \mathrm{~mA} \mathrm{~cm}^{-2}$, respectively. It is worth noting here that only the $i$-layer deposition conditions

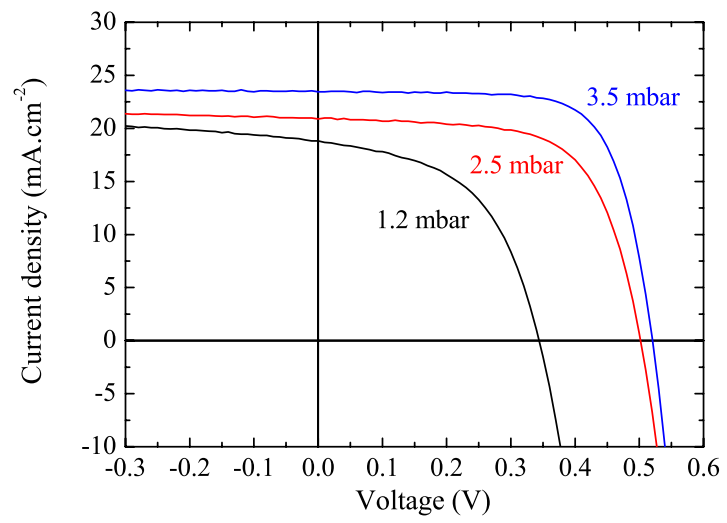

FIG. 1. (Color online) Current-voltage curves of microcrystalline $p-i-n$ cells prepared at 1.2, 2.5, and 3.5 mbar. were changed in order to minimize the differences in the cells strictly linked to the absorber layer. For this reason an identical intrinsic $\mu c$-Si: $\mathrm{H}$ buffer layer at the $p-i$ interface of about $100 \mathrm{~nm}$ was systematically used in all deposition regimes to avoid the influence of the deposition pressure on the underlying $p$-layer and subsequent $p-i$ interface modification.

Another interesting feature of higher $i$-layer deposition pressure is the significant improvement of the spectral response in the red and infrared spectral region as shown in Fig. 2. Considering that the crystalline volume fractions of the intrinsic layers are very similar, the changes could be attributed to modifications in the microstructure. Indeed, a pressure dependence on solar cell performances was already observed in the case of layers deposited at high deposition rate, and the observed differences were attributed to a denser microstructure with larger grains along with a reduction in postdeposition oxidation. ${ }^{28-30}$ However, all the cells prepared in this study were remeasured and did not show any significant postdeposition oxidation, even several months afterward, with the highest loss observed being inferior to $3 \%$ of total short-circuit current density. This may also indicate that the intrinsic layers have similar film density.

\section{B. Study of $\mu c-\mathrm{Si}: \mathrm{H}$ deposition as a function of hydrogen flow rate}

Recently it was shown that it is possible to increase silane depletion, and therefore deposition rate of $\mu c-\mathrm{Si}: \mathrm{H}$, by increasing the gas residence time. ${ }^{31}$ This approach allows to keep rf power density relatively low compared to other deposition processes. ${ }^{5}$ However the question whether these process conditions allow for the deposition of device grade

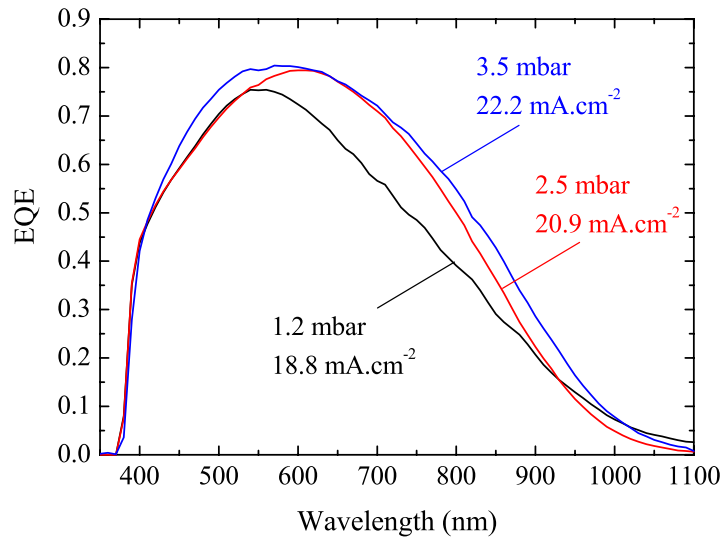

FIG. 2. (Color online) EQEs of microcrystalline $p-i-n$ cells prepared at 1.2, 2.5 , and 3.5 mbar. 


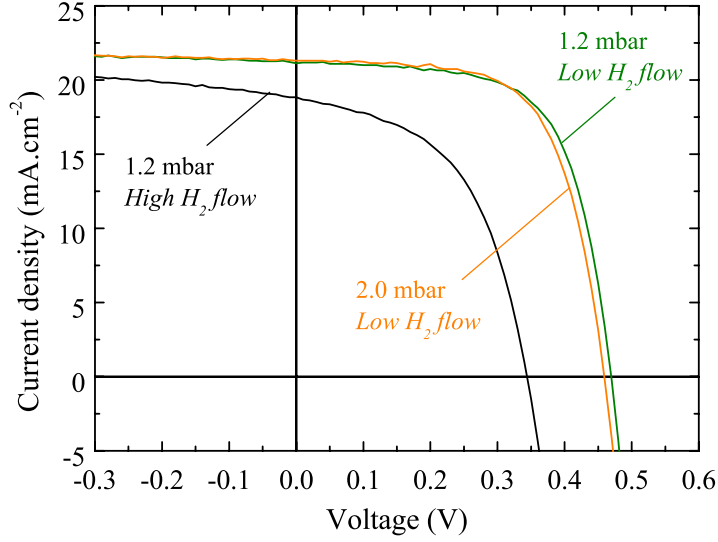

FIG. 3. (Color online) Current-voltage curves of microcrystalline $p-i-n$ cells prepared at 1.2 (low and high silane depletion) and at 2.0 mbar.

$\mu c-\mathrm{Si}: \mathrm{H}$ material was not addressed. For this purpose, two additional regimes were developed in order to study the effects of silane depletion on $\mu c-\mathrm{Si}: \mathrm{H}$ deposition and material quality.

The first deposition regime in high silane depletion is developed at $1.2 \mathrm{mbar}$ in order to establish a comparison with the low silane depletion regime in the same pressure conditions previously discussed. The parameters of the deposition regime at low silane depletion are kept constant but input hydrogen flow, and thus total flow, are lowered following. ${ }^{32}$ This causes on one side an increase in silane concentration $c$, but more importantly it increases the gas residence time in the plasma reactor allowing for a larger fraction of silane to be dissociated, hence increasing $D$. In fact, only minor adjustments are necessary to the rf input power in order to keep the Raman crystallinity fraction unchanged. This can be explained following equation Eq. (2): The increase in $c$ which usually leads to more amorphous material is offset by an increase in $D$ so that the relevant parameter for $\mu c-\mathrm{Si}: \mathrm{H}$ growth $c_{p}$ remains unchanged. Reducing the hydrogen flow by a factor of 7 (raising silane concentration to $21 \%$ ), and slightly increasing the power density, silane depletion goes up to $80 \pm 5 \%$ which explain the enhanced growth rate observed in these regimes, going from $R=2.9$ to $R=6.5 \AA \mathrm{s}^{-1}$ in this case.

A second deposition regime in high silane depletion condition was developed at a pressure of $2.0 \mathrm{mbar}$ and silane concentration of $50 \%$, further increasing the deposition rate up to $R=8.9 \AA \mathrm{A} \mathrm{s}^{-1}$. Silane depletion fraction is estimated in this second case to $70 \pm 5 \%$. Tests at higher pressures have been made, however powder formation increases significantly and no stable process could be found.

Solar cells were deposited with intrinsic layers prepared in those two regimes, near the transition region and with Raman crystallinity of about $50 \%-60 \%$. The $I-V$ curves from the best cells obtained in those two regimes are shown in Fig. 3. For comparison the cell deposited at 1.2 mbar under low silane depletion conditions is reproduced as well. Improvements are observed for cells prepared in higher silane depletion conditions. $V_{\mathrm{oc}}, \mathrm{FF}$, and $J_{\mathrm{sc}}$ are all increased significantly, going from 0.34 to $0.48 \mathrm{~V}$, from $52 \%$ to $66 \%$, and from 18.8 to $21.1 \mathrm{~mA} \mathrm{~cm}^{-2}$, respectively, and this despite

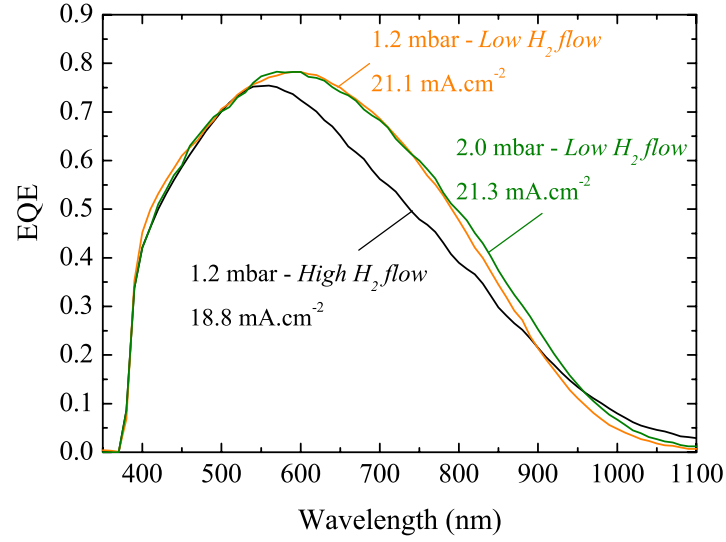

FIG. 4. (Color online) EQEs of microcrystalline $p$ - $i$ - $n$ cells prepared at 1.2 (low and high silane depletion) and at 2.0 mbar.

the increase in deposition rate which is usually a parameter that decreases material quality and solar cell efficiency. ${ }^{33}$ The spectral response of those cells show a similar behavior to the one observed for the cells deposited at different pressures (see Fig. 4). The increase in silane depletion mainly affects the infrared part of the spectrum increasing the EQE at longer wavelengths for comparable cell thicknesses .

\section{Defect density of the intrinsic layer}

In order to understand the origin of the improvement of the solar cells with pressure and depletion, further tests are carried out to analyze the material defect density. This was done through FTPS measurements, and the results can be seen in Fig. 5. The value of the FTPS absorption coefficient at $0.8 \mathrm{eV}$ correlates consistently with solar cell efficiencies. ${ }^{33}$ For instance, the solar cell having the intrinsic layer prepared at 3.5 mbar shows a sub-band-gap absorption coefficient way below the cells having the intrinsic layer deposited at 1.2 and 2.5 mbar. At $0.8 \mathrm{eV}$ a difference of more than one order of magnitude is observed, indicating that the defect density of the material is indeed significantly lowered when deposited at higher pressure. The correlation with the overall electrical

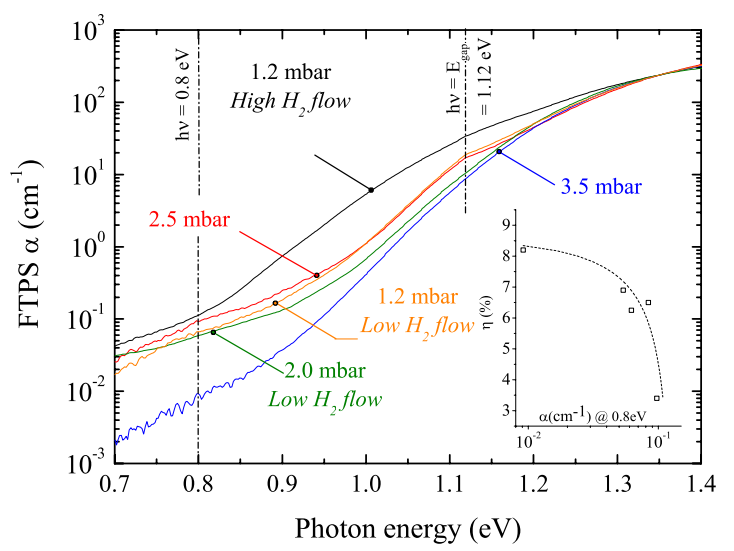

FIG. 5. (Color online) Sub-band-gap absorption coefficient obtained by FTPS measurements on $\mu c-\mathrm{Si}: \mathrm{H} p-i-n$ solar cells prepared at 1.2, 2.5, and 3.5 mbar low depletion regimes and 1.2 and 2.0 mbar high depletion regimes with the same $\mathrm{ZnO}$ as back and front contacts developed at the IMT. The inset shows the efficiency as a function of absorption coefficient at 0.8 $\mathrm{eV}$. The dotted line is a guide to the eye. 


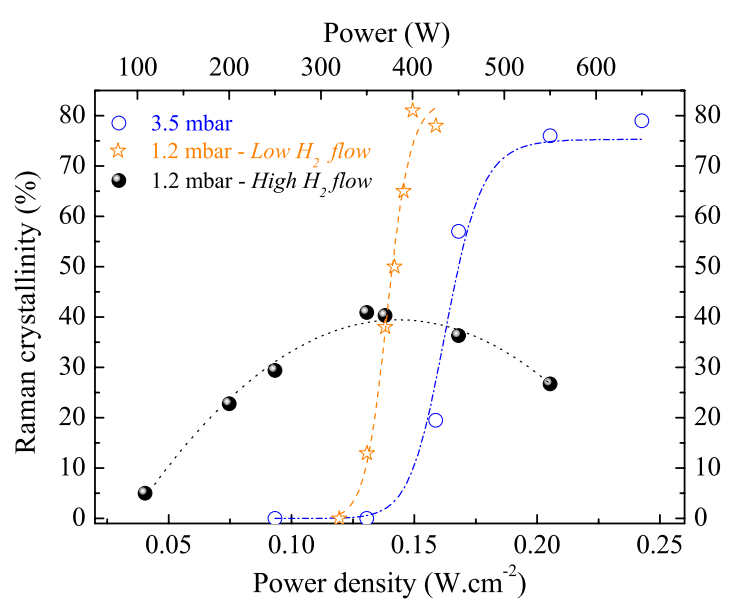

FIG. 6. (Color online) Raman crystallinity as a function of input power for three regimes, at $1.2 \mathrm{mbar}$ (low and high silane depletion) and $3.5 \mathrm{mbar}$. The dashed and dotted lines are a guide to the eye.

cell performances is clear, leading to higher $V_{\mathrm{oc}}, \mathrm{FF}$, and $J_{\mathrm{sc}}$ for low midgap defect density material. Solar cells were deposited on other textured $\mathrm{ZnO}$ as well and the same trend was observed, i.e., the defect density is lowered as the pressure is increased, ensuring that this result is independent of the substrate used. The improvement observed upon increasing silane depletion can be correlated with FTPS measurements as well, showing that the cell deposited at high silane depletion at 1.2 mbar has a lower defect absorption value than the one deposited at low silane depletion.

With regard to the exact location where most of the defects reside, the authors are led to believe that these are located within the crystalline grains themselves rather than at the grain boundaries: This hypothesis is supported by the fact that postdeposition oxidation, which is not observed in any of our cells, has shown to be related to poor grain surface passivation. ${ }^{5}$

We interpret the difference of material quality observed with a varying pressure and silane depletion as an indication that ion bombardment energy, among other plasma mechanisms, plays an important role in the deposition process. As the deposition pressure is lowered, the capacitive sheaths become less collisional, allowing more ions to impinge on the substrate's surface with higher energy, which in return is detrimental to the material quality. In the case of increasing silane depletion, achieved by reducing the hydrogen and total gas flow rate, it will be shown that a reduction of ion bombardment is the result of decreasing time-averaged plasma potential (cf. Fig. 7), although it is unlikely to explain entirely the material and cell improvement, as will be discussed in Sec. III E.

\section{Amorphous to microcrystalline transitions}

To support our interpretation in terms of ion bombardment, the influence of power on the amorphous to microcrystalline transition is investigated in three regimes. Starting with the deposition parameters used for the solar cells giving a Raman crystallinity in the "transition zone" (i.e., $R_{c}$ around $50 \%$, the power is increased and decreased in order to cover it completely. The results are given in Fig. 6 for three depo-

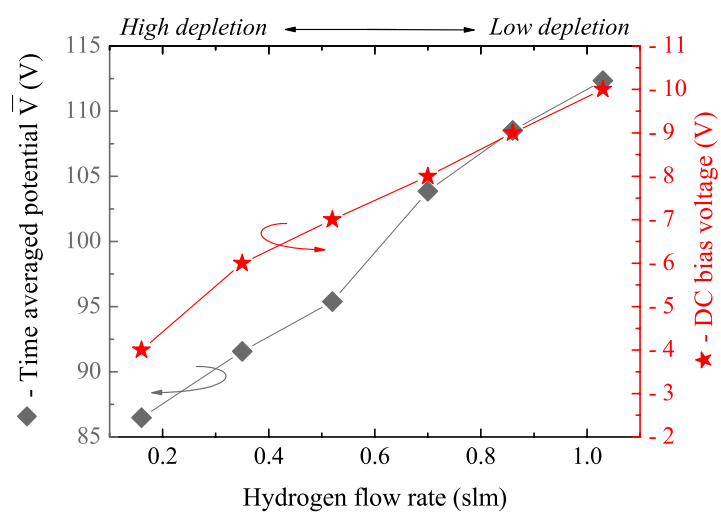

FIG. 7. (Color online) Time-averaged plasma potential (black lozenges) and DC bias voltage (red stars) as a function of the hydrogen flow rate in the 1.2 mbar regime.

sition regimes: at $1.2 \mathrm{mbar}$ in high and low silane depletion conditions and at 3.5 mbar in low depletion conditions.

Varying the power density the three regimes exhibit quite different behaviors. At 3.5 mbar the increase in power density of the discharge results in a monotonous increase of the crystallinity, going as expected from a complete amorphous phase at a low power of $0.14 \mathrm{~W} \mathrm{~cm}^{-2}$, to a highly crystalline material at high power, i.e., $R_{c}=79 \%$ at $0.25 \mathrm{~W} \mathrm{~cm}^{-2}$. On the other hand, at $1.2 \mathrm{mbar}$ and in low depletion conditions the crystallinity first increases between 0.04 and $0.14 \mathrm{~W} \mathrm{~cm}^{-2}$, going from $29 \%$ to $41 \%$, and then steadily decreases to a value of $27 \%$ at $0.21 \mathrm{~W} \mathrm{~cm}^{-2}$. At the same pressure of $1.2 \mathrm{mbar}$, but in high depletion conditions, the transition curve is again recovered and high values of crystallinity around $80 \%$ are reached.

The significant differences observed here between these regimes may be due to multiple factors, among which powder formation or ion bombardment energy seem to be the most reasonable in this context. ${ }^{31}$ However in the 1.2 mbar regime silane partial pressure is lower and powder formation should be less promoted in this case. For this particular reason, it is suspected that the decrease in crystallinity observed at lower pressure is due to a stronger ion bombardment which can induce amorphization. At 3.5 mbar the capacitive sheaths being more collisional, it is expected that the ions impinging the substrate's surface tend to lose a larger portion of their average kinetic energy.

It should also be mentioned here that because of the reactor's geometry, which is close to symmetric, ion bombardment is intrinsically higher compared to a typical asymmetric laboratory reactor due to the area law. ${ }^{34}$ This may partly explain why amorphization can be observed even at moderate power densities, as in our case.

The fact that, in Fig. 6, the transition measured in the deposition regime at $1.2 \mathrm{mbar}$ in high silane depletion conditions does not show a decrease in crystallinity is an indication that ion bombardment is reduced as well. However, contrary to the measurements performed at different pressure values, the origin of the reduced ion energy as silane depletion is increased is not straightforward. To understand this effect we performed a supplementary set of plasma potential measurements as a function of hydrogen flow rate in order to 


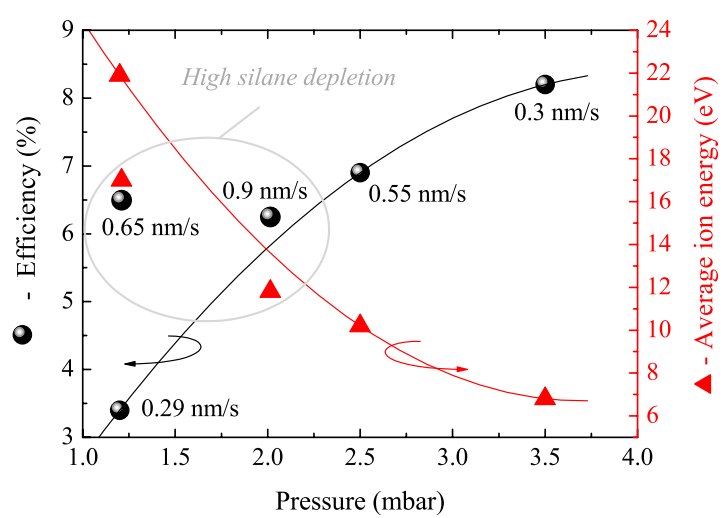

FIG. 8. (Color online) Average solar cell efficiency as a function of deposition pressure and silane depletion for the intrinsic layer (black spheres). The average ion energy was calculated for each deposition regime (red triangles) and is correct within a factor of 2 . The lines are a guide to the eye for the low silane depletion regimes.

get an independent confirmation of the fact that an actual voltage drop occurs upon decreasing the hydrogen flow. This can be seen clearly in Fig. 7, where time-averaged plasma potential (determination detailed in Sec. III E) and self-bias voltage generated on the cathode decrease with decreasing hydrogen flow. The most likely physical reason is a decrease in plasma potential driven by the higher silane concentration. High silane concentrations as in this case tend to reduce electron density and hence ion energy because the plasma becomes more electronegative due to slow electron attachment processes. $^{31,35}$

\section{E. Simple model for ion bombardment energy}

In order to assess the reproducibility of the processes developed in different pressure and silane depletion conditions, several solar cells (minimum of four to maximum of sixteen) were deposited in each deposition regime. The average efficiencies obtained in these regimes are given in Fig. 8. Again, there is a clear trend indicating that deposition of $\mu c-\mathrm{Si}: \mathrm{H}$ at higher pressure for the intrinsic layers of $p-i-n$ solar cells is beneficial for the overall performances. In the same figure appear average efficiencies of solar cells deposited in the two regimes in high silane depletion conditions. The estimated average ion energy $\mathcal{E}_{i}$ impinging the surface is indicated as well. It is calculated in the case of collisional sheaths as

$$
\mathcal{E}_{i} \approx 0.62 \frac{\lambda_{i}}{s_{m}} \bar{V}
$$

where $\lambda_{i}$ is the mean free path, $s_{m}$ is the sheath length, and $\bar{V}$ is the time-averaged plasma potential. ${ }^{36}$ The mean free path has been evaluated as $\lambda_{i}=\left(n_{g} \sigma\right)^{-1}$, with $n_{g}$ the gas density in the reactor, and $\sigma$ the collision cross section which was averaged to $2 \times 10^{-15} \mathrm{~cm}^{2}$ based on previous estimations. ${ }^{37}$ In regard to the sheath thickness it did not appear to be significantly affected by the change in pressure in the range of our study, and as such, was taken constant at $1 \mathrm{~mm}$ in our calculations. Also, in our case $V_{\text {dc }}$ is small compared to $V_{\text {p.p. }}$ $(<3 \%)$ hence the capacitive sheath approximation ${ }^{38,39}$ predicts the time average potential $\bar{V}$ as

$$
\bar{V}=\frac{1}{2}\left(V_{\mathrm{rf}}+V_{\mathrm{dc}}\right) \approx \frac{V_{\mathrm{rf}}}{2} \equiv \frac{V_{\text {p.p. }}}{4} .
$$

It can be seen that the ion bombardment energy is scaling in the range between 20 and $5 \mathrm{eV}$ where a previous publication ${ }^{40,41}$ already showed that ion bombardment energy significantly affects crystallinity, thus further supporting our interpretations. The average ion energy has been estimated as well for the deposition regimes in high silane depletion conditions. It appears that in both cases ion energy is reduced as a result of a decrease in electron density, as measured and reported in the previous paragraph. The average value of ion energy computed using Eq. (5) correlates well with the improvement in efficiency observed. Given the approximations in the calculations we consider that the computed values are correct within a factor of 2. For instance, they are in qualitative agreement with ion values measured in similar conditions. ${ }^{42}$

In general, the improvement of the electrical properties of the cells may be due to the presence of a denser microstructure and larger grains as a result of lower ion bombardment energy, as previously observed. ${ }^{19,28,43}$ Local amorphization of the grains through ion bombardment is likely caused by heavy ions through ion-induced $\mathrm{Si}$ bulk displacement mechanism. ${ }^{41}$ Also, when working in capacitively coupled $\mathrm{VHF} \mathrm{SiH}_{4} / \mathrm{H}_{2}$ discharges in this range of pressure, previous studies $^{42,44}$ would tend to suggest that ions, the most likely responsible for this amorphization process, are the monosilicon hydride ion group $\mathrm{SiH}_{m}^{+}$and polysilicon hydride ion groups $\mathrm{Si}_{n \geq 2} \mathrm{H}_{m}^{+}$.

However, for the process regime at $1.2 \mathrm{mbar}$ in high depletion conditions, the reduction in ion bombardment energy seems small compared to the improvement in cell efficiency. This observation points towards the presence of other plasma mechanisms that could improve microcrystalline material quality. We qualitatively evaluated the electron temperature by comparing two molecular hydrogen emission lines $\mathrm{H}_{2} \quad \mathrm{G}_{0} \mathrm{~B}_{0}$ and $\mathrm{H}_{2}$ Fulcher by optical emission spectroscopy. ${ }^{31,45,46}$ According to a recent publication, a reduction in electron temperature can improve the material quality of microcrystalline silicon, by changing the ratio between silane radicals. ${ }^{16}$ The changes observed in the ratio of the two emission lines when increasing silane depletion at 1.2 mbar indicate a slight decrease in electron temperature. However, the changes being small and sometimes within the error of the measurement, at this point it is not clear whether some of the results could be attributed to a contribution from plasma chemistry.

\section{CONCLUSION}

Growth of $\mu c-\mathrm{Si}: \mathrm{H}$ thin films was studied in industrial type medium area $\mathrm{KAI}^{\mathrm{TM}_{-} \mathrm{S}}$ Plasmabox system to evaluate the importance of pressure and silane depletion on the material quality.

Single junction microcrystalline $p-i-n$ cells were prepared with an intrinsic layer deposited between 1.2 and 3.5 mbar near the transition region, in low and high silane depletion regimes. For roughly the same crystallinity, it is observed that solar cells made at higher pressures and silane 
depletion conditions exhibit significantly higher performances in the range of our study. FTPS measurements of $\mu c-\mathrm{Si}: \mathrm{H}$ intrinsic layers embedded within solar cells concur with this observation: With increasing pressure and silane depletion the defect density is significantly lowered, which is an indication that the electronic material quality is improved. Amorphous to microcrystalline transitions as a function of input power density and calculations of the average ion energy impinging on the substrate both support that ion bombardment is responsible for the observed differences.

\section{ACKNOWLEDGMENTS}

The authors would like to thank B. Strahm, A. Howling, and C. Hollenstein from the Centre de Recherches en Physique des Plasmas (CRPP) of Lausanne for useful discussions.

${ }^{1}$ J. Meier, R. Flückiger, H. Keppner, and A. Shah, Appl. Phys. Lett. 65, 860 (1994).

${ }^{2}$ A. V. Shah, J. Bailat, E. Vallat-Sauvain, M. Vanecek, J. Meier, S. Fay, L. Feitknecht, I. Pola, V. Terrazzoni, and C. Ballif, Proceedings of the 31st IEEE Photovoltaic Specialists Conference, Lake Buena Vista, Fla, USA, 2005 (unpublished), pp. 1353-1358.

${ }^{3}$ U. Kroll, J. Meier, P. Torres, J. Pohl, and A. Shah, J. Non-Cryst. Solids 227-230, 68 (1998).

${ }^{4}$ N. Wyrsch, C. Droz, L. Feitknecht, P. Torres, E. Vallat-Sauvain, J. Bailat, and A. Shah, J. Non-Cryst. Solids 299-302, 390 (2002).

${ }^{5}$ A. H. M. Smets, T. Matsui, and M. Kondo, J. Appl. Phys. 104, 034508 (2008).

${ }^{6}$ C. Niikura, M. Kondo, and A. Matsuda, J. Non-Cryst. Solids 338-340, 42 (2004).

${ }^{7}$ T. Kunii, K. Murata, M. Matsumoto, K. Kawamoto, Y. Kobayashi, Y. Aya, M. Nakagawa, A. Terakawa, and M. Tanaka, Proceedings of the 33rd IEEE Photovoltaic Specialists Conference, San Diego, CA, USA, 2008 (unpublished).

${ }^{8}$ M. Noda, T. Nishimiya, K. Yamaguchi, K. Kawamura, H. Sonobe, M. Kuroda, A. Yamada, H. Takatsuka, Y. Yamauchi, and Y. Takeuchi, Proceedings of Third World Conference on Photovoltaic Energy Conversion, Osaka, Japan, 2003 (unpublished), pp. 1849-1851.

${ }^{9}$ E. Amanatides, D. Mataras, and D. E. Rapakoulias, J. Vac. Sci. Technol. A 20, 68 (2002).

${ }^{10}$ Y. Nakano, S. Goya, T. Watanabe, N. Yamashita, and Y. Yonekura, The Joint Meeting of 7th APCPST (Asia Pacific Conference on Plasma Science and Technology) and 17th SPSM (Symposium on Plasma Science for Materials): 7th APCPST/17th SPSM [Thin Solid Films 506-507, 33 (2006).]

${ }^{11}$ B. Rech, T. Repmann, M. N. van den Donker, M. Berginski, T. Kilper, J. Hüpkes, S. Calnan, H. Stiebig, and S. Wieder, Proceedings of Symposium F on Thin Film and Nanostructured Materials for Photovoltaics: EMRS, 2005[Thin Solid Films, 511-512, 548 (2006)].

${ }^{12}$ A. A. Howling, J.-L. Dorier, Ch. Hollenstein, U. Kroll, and F. Finger, J. Vac. Sci. Technol. A 10, 1080 (1992).

${ }^{13}$ W. Schwarzenbach, A. A. Howling, M. Fivaz, S. Brunner, and Ch. Hollenstein, J. Vac. Sci. Technol. A 14, 132 (1996).

${ }^{14}$ L. Sansonnens, A. A. Howling, and Ch. Hollenstein, Plasma Sources Sci. Technol. 7, 114 (1998)
${ }^{15}$ B. Strahm, A. A. Howling, L. Sansonnens, and Ch. Hollenstein, Plasma Sources Sci. Technol. 16, 80 (2007).

${ }^{16}$ C. Niikura, N. Itagaki, and A. Matsuda, Jpn. J. Appl. Phys., Part 1 46, 3052 (2007).

${ }^{17}$ E. A. G. Hamers, A. Fontcuberta i Morral, C. Niikura, R. Brenot, and P. Roca i Cabarrocas, J. Appl. Phys. 88, 3674 (2000).

${ }^{18}$ M. Kondo, M. Fukawa, L. Guo, and A. Matsuda, J. Non-Cryst. Solids 266-269, 84 (2000).

${ }^{19}$ B. Kalache, A. I. Kosarev, R. Vanderhaghen, and P. Roca i Cabarrocas, J. Appl. Phys. 93, 1262 (2003).

${ }^{20}$ J. Bailat, E. Vallat-Sauvain, L. Feitknecht, C. Droz, and A. Shah, J. NonCryst. Solids 299-302, 1219 (2002).

${ }^{21}$ E. Vallat-Sauvain, J. Bailat, J. Meier, X. Niquille, U. Kroll, and A. Shah, Thin Solid Films 485, 77 (2005).

${ }^{22}$ J. Perrin, J. Schmitt, Ch. Hollenstein, A. A. Howling, and L. Sansonnens, Plasma Phys. Controlled Fusion 42, B353 (2000).

${ }^{23}$ A. A. Howling, B. Strahm, P. Colsters, L. Sansonnens, and Ch. Hollenstein, Plasma Sources Sci. Technol. 16, 679 (2007).

${ }^{24}$ E. Vallat-Sauvain, C. Droz, F. Meillaud, J. Bailat, A. Shah, and C. Ballif, J. Non-Cryst. Solids 352, 1200 (2006).

${ }^{25}$ J. Bailat, D. Dominé, R. Schlüchter, J. Steinhauser, S. Faÿ, F. Freitas, C. Bücher, L. Feitknecht, X. Niquille, T. Tscharner, A. Shah, and C. Ballif, Proceedings of the Fourth WCPEC Conference, Kona Island, Hawaii, USA, 2006 (unpublished), pp. 1533-1536.

${ }^{26}$ M. Vanecek and A. Poruba, Appl. Phys. Lett. 80, 719 (2002).

${ }^{27}$ L. Sansonnens, A. A. Howling, and Ch. Hollenstein, Plasma Sources Sci. Technol. 9, 205 (2000).

${ }^{28}$ T. Matsui, M. Kondo, and A. Matsuda, Jpn. J. Appl. Phys., Part 2 42, L901 (2003).

${ }^{29}$ T. Matsui, A. Matsuda, and M. Kondo, Proceedings of the 19th European Photovoltaic Solar Energy Conference, 2004 (unpublished), pp. 14071410 .

${ }^{30}$ M. Kondo, T. Matsui, Y. Nasuno, C. Niikura, T. Fujibayashi, A. Sato, A. Matsuda, and H. Fujiwara, Proceedings of the 31st IEEE Photovoltaic Specialists Conference, Lake Buena Vista, Fla, USA, 2005 (unpublished), pp. 1377-1382.

${ }^{31} \mathrm{~B}$. Strahm, "Investigations of radio-frequency, capacitively-coupled large area industrial reactor: Cost-effective production of thin film microcrystalline silicon for solar cells," Ph.D. thesis, EPFL, 2007.

${ }^{32}$ B. Strahm, A. A. Howling, L. Sansonnens, Ch. Hollenstein, U. Kroll, J. Meier, Ch. Ellert, L. Feitknecht, and C. Ballif, Sol. Energy Mater. Sol. Cells 91, 495 (2007)

${ }^{33}$ A. Gordijn, M. Vanecek, W. J. Goedheer, J. K. Rath, and R. E. I. Schropp, Jpn. J. Appl. Phys., Part 1 45, 6166 (2006).

${ }^{34}$ M. A. Lieberman, J. Appl. Phys. 65, 4186 (1989).

${ }^{35}$ M. Takai, T. Nishimoto, M. Kondo, and A. Matsuda, Thin Solid Films 390, 83 (2001).

${ }^{36}$ M. A. Liebermann and A. J. Lichtenberg, Principles of Plasma Discharges and Materials Processing, 2nd ed. (Wiley-Interscience, New York, 2005).

${ }^{37}$ J. Perrin, O. Leroy, and M. C. Bordage, Contrib. Plasma Phys. 36, 3 (1996).

${ }^{38}$ B. Chapman, Glow Discharge Processes (Wiley-Interscience, New York, 1980).

${ }^{39}$ K. Köhler, D. E. Horne, and J. W. Coburn, J. Appl. Phys. 58, 3350 (1985).

${ }^{40}$ M. Kondo, Sol. Energy Mater. Sol. Cells 78, 543 (2003).

${ }^{41}$ A. H. M. Smets and M. Kondo, J. Non-Cryst. Solids 352, 937 (2006).

${ }^{42}$ S. Nunomura and M. Kondo, Appl. Phys. Lett. 93, 231502 (2008).

${ }^{43}$ S. Lebib and P. Roca i Cabarrocas, J. Appl. Phys. 97, 104334 (2005).

${ }^{44}$ S. Nunomura and M. Kondo, J. Appl. Phys. 102, 093306 (2007).

${ }^{45}$ U. Fantz, Plasma Phys. Controlled Fusion 40, 1035 (1998).

${ }^{46}$ U. Fantz, Plasma Sources Sci. Technol. 15, S137 (2006). 